\title{
Prevalence and determinants of contraceptives use among rural young women (15-24 years) in Ghana
}

Mohammed Gazali Salifu ( $\triangle$ mohammedgazali17@gmail.com )

Ministry of Health Ghana https://orcid.org/0000-0003-2025-5337

Kamaldeen Mohammed

Department of Geography, Western University

Mac-Cauley Harrison

Adidome Government Hospital, Adidome

Aaron Atimpe

Ministry of Finance, Ghana

Rogers Wuniwumda Abukari

University for Development Studies

Vasco Ayere Avoka

Ministry of Health, Ghana

Mubarik Abdul-Rahman

University for Development Studies

\section{Research Article}

Keywords: prevalence, contraceptives, maternal health, rural women, predictor, Ghana

Posted Date: April 28th, 2020

DOI: https://doi.org/10.21203/rs.3.rs-25494/v1

License: (9) This work is licensed under a Creative Commons Attribution 4.0 International License.

Read Full License 


\section{Abstract}

Background: Contraceptives use has significant effect on controlling fertility, preventing STIs, reducing unwanted pregnancies and induced abortions. The use of contraceptives among reproductive age women (15-49 years) has been largely reported. However, what is unclear is whether the reported prevalence of, and factors that influence the usage of contraceptives is comparable in the context of young adults (aged 15-24 years) in rural areas. The purpose of this study was therefore to report the prevalence and factors that influence contraceptives use among young women (15-24 years) in rural Ghana.

Methods: Data $(n=3797)$ collected using a questionnaire through a mutli-stage probability sampling method in the 2017 Ghana Maternal Health Survey (GMHS) was analyzed by descriptive and inferential statistical methods. The chi-square test was used to identify significant associations between categorical variables at a significant level of $p<0.05$. Univariate and multivariate logistic regression analyses was conducted to explore how well each independent variable predicted contraceptive use.

Results: Out of the 3,797 women, only $21.49 \%(95 \% \mathrm{Cl}$ : $19.56,23.55)$ used contraceptives. Number of living children, health insurance, knowledge of fertility period, history of abortion, ever given birth, educational level, age of participants and current union were found to influence contraceptives use. Strong significant predictors (at $95 \% \mathrm{Cl}, \mathrm{p}<0.05$ ) of contraceptives use were history of abortion, age of participants, educational level, number of living children, and knowledge of fertility period.

Conclusion: Low usage of contraceptives has been identified among rural women and so there is the need for policymakers to intensify education and facilitate widespread access to modern contraceptives in rural areas and promote their effective use.

\subsection{Introduction}

In Sub-Saharan Africa (SSA), approximately $21-28 \%$ of women aged 10-19 years have had their first sex experience before age 15 (Berhane et al., 2020). In Ghana, 9\% of women aged $15-19$ years and $12 \%$ of women aged 20-49 years have had sexual intercourse by age 15 years, $49 \%$ of women aged 20-49 years have had sex by age 18 years and $73 \%$ by age 20 years (Ghana Statistical Service, Ghana Health Service, \& ICF International, 2017). In addition, rural women aged 20-49 years start having sex a year earlier than urban women with 17.5 years median age at first sex compared with 18.5 years median age among urban women (Ghana Statistical Service, Ghana Health Service, \& ICF International, 2017). Furthermore, only $25 \%$ of currently married women aged $15-49$ years and $31 \%$ of sexually active unmarried women aged 15-49 years use a modern method of contraception (Ghana Statistical Service, Ghana Health Service, \& ICF International, 2017). 
Although modern contraceptives use in Ghana among women in reproductive age (15-49 years) have been on the increase from $5 \%$ (1988), 8.75\% (2003), 15.75\% (2008), 21.53\% (2014) and 25\% (2017) (Aviisah et al., 2018; Ghana Statistical Service, Ghana Health Service, \& ICF International, 2017) usage remains unsatisfactory among women in reproductive age.

Modern contraceptives have contributed to reduced maternal deaths (Ahmed et al., 2012) and Sexually Transmitted Infections (STIs) such as HIV/AIDs, Syphilis, and Gonorrhea (Kirkman \& Chantler, 1993), and reduced incidence of unwanted pregnancies and induced abortions (Geelhoed et al., 2002). However, contraceptive use has been implicated in undesirable outcomes among rural Ghanaian women such as heavier bleeding, amenorrhea or oligomenorrhea, complications with childbirth, and infertility (Schrumpf et al., 2020).

The use of contraceptives among reproductive age women (15-49 years) has been largely reported in the literature (Aviisah et al., 2018; Bakibinga et al., 2016; Goldenberg \& Stephenson, 2019; Kanwal et al., 2017). However, what is unclear is whether the reported prevalence of, and factors that influence the, usage of contraceptives is comparable in the context of young adults (aged 15-24 years). Reported prevalence rates of contraceptive use among women have been 18\% (ages 16-19 years), 49.2\% (ages 1318 years), and 44\% (ages 18-24 years) (Agyemang et al., 2019; Grindlay et al., 2018; Odonkor et al., 2012).. The reports show that modern contraceptives use vary across the regions of Ghana (Nyarko, 2020), with an annual increase of about 3.66\% (2.81-4.47\%) among those aged 15-49 years (Ahmed et al., 2019). Factors such as place of residence, education, (Aviisah et al., 2018), occupation, marriage (Agyemang et al., 2019), reading newspapers, and watching television (Appiah et al., 2020) are believed to influence contraceptives use.

The varying age stratum prevalence and associated factors make it imperative to critically look at the use of contraceptives and the associated factors among women stratified by age in specific settings. This study therefore focused on adolescents and young women (ages 15-24 years) in rural settings in Ghana using a large national representative survey, the Ghana Maternal Health Survey (GMHS), 2017.

\subsection{Materials \& Methods}

\subsection{Study design and Data source}

This study analyzed secondary data from the 2017 Ghana Maternal Health Survey (GMHS), with focus on data from rural Ghana. The GMHS is a nationally representative special Demographic and Health Survey (DHS) that collects data pertaining to women, children, births, households and other feminine variables covering all regions of the country. The survey has been conducted twice in Ghana; in 2007 and 2017. This study therefore employed a retrospective cross-sectional design.

\subsection{Sampling Approach and Study Population}


The 2017 GMHS sample was stratified and selected from the sampling frame in two stages. Each region was separated into urban and rural areas; this yielded 20 sampling strata. Samples of Enumeration Areas (EAs) were selected independently in each stratum in two stages. Implicit stratification and proportional allocation were achieved at each of the lower administrative levels by sorting the sampling frame within each sampling stratum before the sample selection, according to administrative units at different levels, and by using a probability proportional to size selection at the first stage of sampling.

In the first stage, 900 EAs (466 EAs in urban areas and 434 EAs in rural areas) were selected with probability proportional to EA size and with independent selection in each sampling stratum. A household listing operation was implemented from 25 January to 9 April 2017 in all of the selected EAs. The resulting lists of households then served as a sampling frame for the selection of households in the second stage. The household listing operation included inquiring of each household if there had been any deaths in that household since January 2012 and, if so, the name, sex, and age at time of death of the deceased person(s). Some of the selected EAs were very large. To minimise the task of household listing, each large EA selected for the 2017 GMHS was segmented. Only one segment was selected for the survey with probability proportional to segment size. Household listing was conducted only in the selected segment. Thus, in the GMHS, a cluster is either an EA or a segment of an EA. In order to get statistics that are representative of Ghana, the distribution of the women in the sample was weighted (or mathematically adjusted) such that it resembles the true distribution in the country. Therefore, a calculated "weight" by DHS was used to adjust the number of women from each region so that each region's contribution to the total is proportional to the actual population of the region (Ghana Statistical Service, Ghana Health Service, \& ICF International, 2017).

For the GMHS 2017, a total of 27,001 households were selected for the sample, of which 26,500 were occupied at the time of fieldwork. Of the occupied households, 26,324 were successfully interviewed, yielding a response rate of $99 \%$. In the interviewed households, 25,304 eligible women were identified for individual interviews; interviews were completed with 25,062 women, yielding a response rate of $99 \%$.

In this study, data on 3,797 women in rural residents between the ages of 15 and 24 years out of the 25,062 reproductive age women were analyzed.

\subsection{Outcome variable, inclusion and exclusion criteria}

The outcome variable of interest is "current usage of contraceptives". Participants were asked the question: "Are you or your partner currently doing something or using any method to delay or avoid getting pregnant?"; whose responses were coded as either "Yes" or "No". The number of participants who responded either "Yes" or "No" to the question after data manipulation and with only complete case analysis (respondents with no missing information) were 3,797. Only data on women within the ages of 15-24 years were included while those with missing data variables were excluded from the analysis. 


\subsection{Independent variables measures}

Pertinent independent variables were considered for the analysis. Age group was recategorized into '1419 ' and '20-24', religious status was grouped into 'Christianity', 'Islamic', 'Traditional' and 'Others'. Parity was classified at 2-scale level as 0 , and 1+. Level of education was classified as 'primary', 'secondary' or 'higher'. The following variables were measured on a 'Yes' or 'No' outcome: health insurance, abortion history, dichotomous childbirth, knowledge about fertility, and current union. Region of origin was classified according to Eastern, Greater Accra, Northern, Upper East, Upper West, Volta, Eastern, Central, Ashanti, Western, and Brong Ahafo. These were the ten regions of Ghana at the time this data was collected.

\subsection{Statistical Analysis}

This study used both descriptive and inferential methods to analyze the data. Descriptive statistics used included frequencies and percentages. Both bivariate and multivariable techniques were used to assess statistical associations between the outcome variable and the predictors. The bivariate technique was applied to obtain predictors that had a statistically significant relationship with the outcome of interest (current contraceptive use). In this approach, factors that were statistically significantly associated with the outcome were a chi-squared test of independence with the help of their confidence intervals $(\mathrm{Cl})$ and p-values. $p$-value less than or equal to 0.05 was used to retain and include variables in the multivariable analysis level to estimated the odds ratios (ORs). In multivariate analysis, a binary logistic regression analysis was performed at three $(4)$ levels to determine which factors significantly predict $(p<0.05)$ the probability of using contraceptives. Multicollinearity was detected with a reasonable assumption if the magnitude of standard error (SE) of each variable fell within acceptable defined level such as (0.001-5.0) (Chan, 2004). This statistical approach was implemented in STATA (Stata Statistical Software: Release 16. College Station, TX: StataCorp LP) software.

\subsection{Results}

\subsection{SOCIO-DEMOGRAPHIC CHARACTERISTICS OF STUDY PARTICIPANTS}

A total of 3,797 women met the inclusion criteria for the study. The mean (standard deviation (SD)) age in years of the women was $18.74(2.86)$. Out of the 3,797 , about $78.51 \%$ did not use any type of contraceptive while $21.49 \%$ used contraceptives (Table1). The mean (SD) age in years of respondents who did not use any contraceptive was 18.23 (2.79) while that of those who used contraceptives was 20.63 (2.31) respectively.

Majority of the study participants were between the ages of 15 and 19 years, representing $60.87 \%$ of the total number of participants, while $39.13 \%$ of them were between the ages of 20 and 24 years (Table 1 ). 
All study participants had some level of education, largely dominated with primary level education (78.63\%). Most participants were Christians, constituting (84.54\%) (Table 1).

Table 1 Showing socio-demographics distribution of study participants 


\begin{tabular}{|c|c|c|c|}
\hline Variable & Categories & Frequency & Percentage \\
\hline \multicolumn{4}{|c|}{ Age(years) } \\
\hline & $15-19$ & 2355 & 60.87 \\
\hline & $20-24$ & 1442 & 39.13 \\
\hline \multicolumn{4}{|l|}{ Religion } \\
\hline & Christianity & 2933 & 84.54 \\
\hline & Islamic & 753 & 12.15 \\
\hline & Traditional & 54 & 1.49 \\
\hline & Others & 57 & 1.82 \\
\hline \multicolumn{4}{|c|}{ Education } \\
\hline & Primary & 3007 & 78.63 \\
\hline & Secondary & 725 & 19.48 \\
\hline & Higher & 65 & 1.898 \\
\hline \multicolumn{4}{|c|}{ Number of living children } \\
\hline & 0 & 2476 & 62.58 \\
\hline & 1 and above & 1321 & 37.42 \\
\hline \multicolumn{4}{|c|}{ Knowledge of fertility period } \\
\hline & Yes & 2716 & 76.97 \\
\hline & No & 1081 & 23.03 \\
\hline \multicolumn{4}{|l|}{ Union } \\
\hline & Yes & 995 & 25.03 \\
\hline & No & 2802 & 74.97 \\
\hline \multicolumn{4}{|c|}{ Contraceptives use } \\
\hline & Yes & 725 & 21.49 \\
\hline & No & 3072 & 78.51 \\
\hline \multicolumn{4}{|c|}{ Health Insurance } \\
\hline & Yes & 3009 & 74.35 \\
\hline & No & 788 & 25.65 \\
\hline \multicolumn{4}{|c|}{ Abortion history } \\
\hline & Yes & 220 & 8.144 \\
\hline & No & 3577 & 91.86 \\
\hline & Page 7/18 & & \\
\hline
\end{tabular}




\begin{tabular}{|c|c|c|c|}
\hline \multicolumn{4}{|l|}{ Ever given birth } \\
\hline & Yes & 1157 & 32.07 \\
\hline & No & 2640 & 67.93 \\
\hline \multicolumn{4}{|l|}{ Region } \\
\hline & Greater accra & 75 & 4.387 \\
\hline & Ashanti & 358 & 17.03 \\
\hline & Volta & 274 & 11.71 \\
\hline & Northern & 535 & 7.263 \\
\hline & Upper west & 654 & 4.637 \\
\hline & Upper east & 616 & 5.872 \\
\hline & Eastern & 338 & 12.04 \\
\hline & Western & 375 & 16.98 \\
\hline & Central & 217 & 9.141 \\
\hline & Brong ahafo & 355 & 10.95 \\
\hline
\end{tabular}

\subsection{Determinants of current contraceptive usage}

Pearson Chi-squared $\left(\chi^{2}\right)$ test was used to assess the association between current contraceptive use and some selected sociodemographic indicators. Contraceptive use was found to be strongly associated (Table 2) with the number of living children $\left(\chi^{2}=422.49, p=0.000\right)$, Age(years) of participants $\left(\left(x^{2}=325.6510, p=0.000\right)\right.$, health insurance registration $\left(\chi^{2}=14.94, p=0.000\right)$, knowledge of fertility period $\left(\chi^{2}=119.496, p=0.000\right)$, abortion history $\left(\chi^{2}=223.77, p=0.000\right)$, ever given birth $\left(\chi^{2}=296.18, p=0.000\right)$, level of education $\left(\chi^{2}=33.122, p=0.000\right)$, and current union $\left(\chi^{2}=61.67, p=0.000\right)($ Table 2$)$.

Table 2 Percentage of women who use any contraceptive according to their socio- demographic characteristicsand Chi- square analysis of associations. 


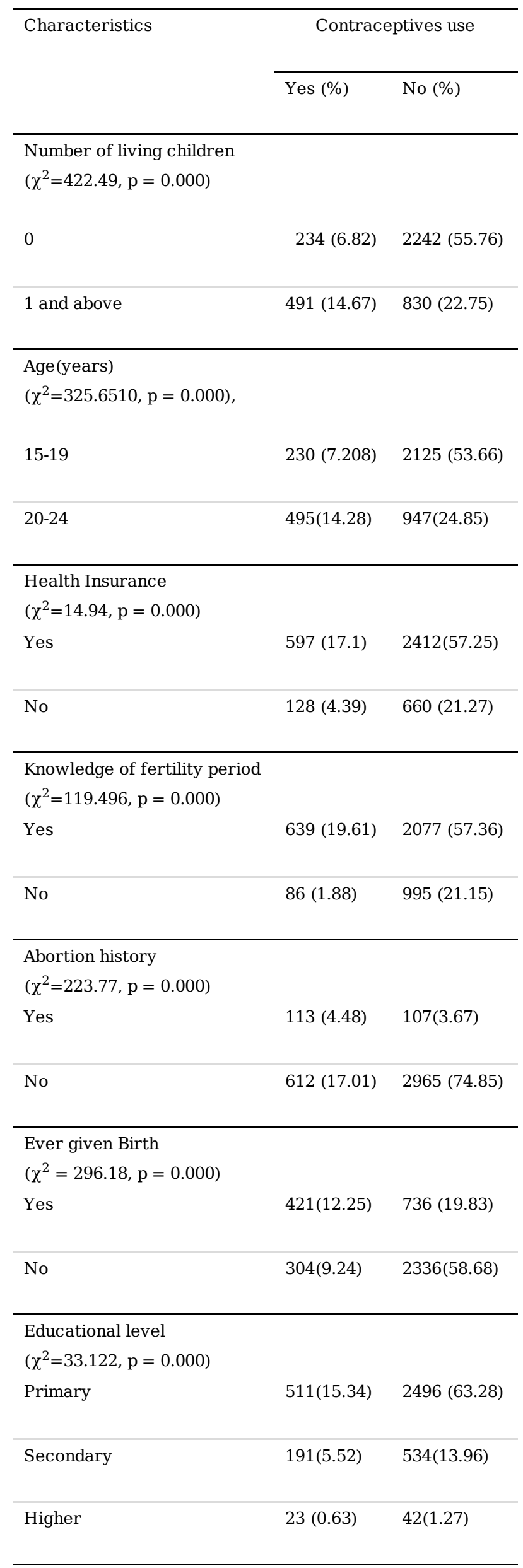


To explore how well each independent variable predicted contraceptive use, we conducted a univariate and multivariate logistic regression analyses (Table 3).

In step1 (ST1), (Table 3) number of living children(nlc), age of participants(ag), knowledge of fertility period(kfp), abortion history(abh) , health insurance (hi), ever given birth(evg), educational level(edu), region(re) and current union(cu) were each identified to be significant predictors of contraceptives use without any adjustments(Table 3).

Participants who had one or more living children were 5.27 (95\% Cl:4.10-6.77, p = 0.000) times more likely to use contraceptives compared to those without living children. Participants aged 20-24years were 4.28 (95\% Cl: $3.25-5.62, p=0.000$ ) times more likely to use contraceptives compared to those aged 15-19 years. Participants who knew their fertility period were $3.84(95 \% \mathrm{Cl}: 2.86-5.12, \mathrm{p}=0.000)$ times more likely to use contraceptives against those who did not. The probability of using contraceptives was 5.37 (95\% Cl:3.97- 7.57, $p=0.000)$ times among participants with abortion history compared with those without any abortion history; health insured participants were 1.45 (95\% Cl:1.11-1.91, $p=0.009)$ times more likely contraceptives users than those without any form of health insurance, participants who had ever given birth before were $3.92(95 \% \mathrm{Cl}: 3.05-5.04, \mathrm{p}=0.000)$ more likely to use contraceptives compared with those with no birth history. Secondary education and higher education increased the chances of contraceptives use among participants by 1.63 (95\% Cl:1.27-2.09, $\mathrm{p}=0.000)$ and 2.04 (95\% Cl: 1.04-4.00, $p=0.000$ ) times compared to those participants who had primary education only. Participants currently married or in union with a man were $3.43(95 \% \mathrm{Cl}: 2.70-6.77, \mathrm{p}=0.000)$ times more likely to use contraceptives compared with others not in union.

In Step 2 (ST2), (Table 3). after adjusting for kfp, abh, hi, egb, el, ag, and cu, participants who had one or more living children were now $2.82(95 \% \mathrm{Cl}$ : 1.60-4.97, $\mathrm{p}=0.000)$ times more likely to use contraceptives compared with their counterparts without living children. Participants aged 20-24years were now 1.76(95\% Cl: $1.21-2.55, \mathrm{p}=0.003)$ times more likely to use contraceptives compared to those aged 15-19 years, after adjusting for $\mathrm{kfp}$, abh, hi, egb, el, nlc, and cu. In addition, the probability of contraceptives use among those who knew their fertility period was $2.44(95 \% \mathrm{Cl}: 1.76-3.37, \mathrm{p}=0.000)$ times more likely, after controlling for nlc, abh, hi, egb, ag, el, and cu, compared with those who did not know. Participants with history of abortion were 2.22 (95\% Cl: $1.45-3.40, p=0.000)$ times more likely to use contraceptives after adjusting for $\mathrm{nlc}, \mathrm{kfp}$, hi, egb, ag, edu, and cu than those without any abortion history. Furthermore, after controlling for the other predictive factors, health insurance(hi), current union(cu) and ever given given(egb) were statistically insignificant predictors of contraceptive use among the participants. Participants with secondary education and higher education were $1.77(95 \% \mathrm{Cl}: 1.32-2.73, \mathrm{p}=0.000)$ and 2.25 (95\% Cl: $1.05-4.85, p=0.038)$ more likely to use contraceptives compared to those with only primary education after adjusting for nlc, abh, hi, egb, ag, kfg, and cu.

In step 3, (Table 3) participants who had one more living children were 3.43 (95\% Cl: 2.55-4.61, p = 0.000) times more likely to use contraceptives compared with those without any living children after adjusting 
for kfg, abh, edu, and ag. Participants aged 20-24years were 1.83(95\% Cl: 1.30-2.59, p=0.003) times more likely to use contraceptives compared to those aged 15-19 years, after adjusting for kfg, abh, edu, and nlc.

After controlling for [nlc, abh, edu, ag], participants with knowledge of their fertility period were 2.45 ( $95 \%$ $\mathrm{Cl}: 1.78-3.40, p=0.000$ ) times more likely to use contraceptives compared with those who did not know their fertility period. Participants with any abortion history were $2.20(95 \% \mathrm{Cl}: 1.41-2.87, \mathrm{p}=0.000)$ more likely to use contraceptives after adjusting for [kfg, edu,pa, ag] compared with those without any abortion history. After controlling for [abh, $\mathrm{kg}, \mathrm{nlc}, \mathrm{ag}]$ participants who had secondary and higher education were $1.75(95 \% \mathrm{Cl}: 1.32-2.33, \mathrm{p}=0.000)$ and $2.25(95 \% \mathrm{Cl}: 1.06-4.80, \mathrm{p}=0.036)$ times more likely users of contraceptives compared with those with only primary education (Table 3 ).

Table 3 The odds ratio of logistic regression models for the determinants of current use of contraceptives. 


\begin{tabular}{|c|c|c|}
\hline ST 1: OR (95\% CI) & ST2: aOR (95\% CI) & ST3: aOR $(95 \%$ CI $)$ \\
\hline \multicolumn{3}{|l|}{ ing children } \\
\hline 1 & 1 & 1 \\
\hline $5.27(4.10-6.77)$ & $2.82(1.60-4.97)$ & $3.43(2.55-4.61)$ \\
\hline 0.000 & 0.000 & 0.000 \\
\hline 1 & 1 & 1 \\
\hline $4.28(3.25-5.62)$ & $1.76(1.21-2.55)$ & $1.83(1.30-2.59)$ \\
\hline 0.000 & 0.003 & 0.001 \\
\hline
\end{tabular}

fertility period

\begin{tabular}{ccc}
1 & 1 & 1 \\
\hline $3.84(2.86-5.12)$ & $2.44(1.76-3.37)$ & $2.45(1.78-3.40)$ \\
0.000 & 0.000 & 0.000 \\
\hline
\end{tabular}

:ory

1

1

1.45 (1.11-1.91)

1.13 (0.84-1.52)

REM

0.009

0.433

2.20(1.41-2.87)

0.000

\begin{tabular}{|c|c|c|}
\hline th & & \\
\hline 1 & 1 & \\
\hline $3.92(3.05-5.04)$ & $1.11(0.66-1.86)$ & REM. \\
\hline 0.000 & 0.689 & \\
\hline vel & & \\
\hline 1 & 1 & 1 \\
\hline $1.63(1.27-2.09)$ & $1.77(1.32-2.73)$ & $1.75(1.32-2.33)$ \\
\hline 0.000 & 0.000 & 0.000 \\
\hline $2.04(1.04-4.00)$ & $2.25(1.05-4.85)$ & $2.25(1.06-4.80)$ \\
\hline 0.037 & 0.038 & 0.036 \\
\hline ion & & \\
\hline 1 & 1 & 1 \\
\hline $3.43(2.70-6.77)$ & $1.17(0.83-1.67)$ & REM \\
\hline
\end{tabular}

Page 12/18 
$\mathrm{ST}=\mathrm{Step}, \mathrm{OR}=$ crude odds ratio, $\mathrm{aOR}=$ adjusted odds ratio, $\mathrm{CI}=$ Confidence Interval

\subsection{Discussions}

This study made use of the GMHS 2017 data by pointing out observed differences in the prevalence and predictive factors influencing contraceptives use among rural women aged 15-24 years. The age group 15-24 years was chosen for the purpose of this study because previous studies have reported that $9 \%$ of women aged 15-19 years) have had sexual intercourse by age 15 years, and $49 \%$ of women aged 20-49 years have had sex by age 18 years, and $73 \%$ by age 20 years. The lower age range was then chosen since it is the period within which sexual intercourse initiates, and comprises younger women who are most sexually active compared to the other age categories. Our focus on rural women was also informed by the fact that rural women in Ghana have inadequate or difficulties in accessing maternal and child health services including family planning education compared to urban areas (Buor, 2004). However, contraceptives use is reported to be increasing among rural women in Ghana relative to urban women (Aviisah et al., 2018; Nonvignon \& Novignon, 2014). Factors that commonly influence the use of contracepts among the 15-24 years age group were explored, and these included knowledge of their fertile period, abortion history, educational level and the number of living children.

Contraceptives use was found to be low among the study participants as only $21.49 \%$ of them $(n=3,797)$ were current contraceptives users. This study corroborates similar studies that have found low contraceptives use among various age groups nested within our age stratum (15-24years). In rural Atwima Kwanwoma District in the Ashanti region of Ghana, Agyemang et al. (2019) found that $18 \%$ of women aged 16-19 years used contraceptives. Appiah et al. (2020) however found contraceptives use among women aged 15-16 years to have decreased by almost 2\% between 2003 (22.1\%) and 2014 (20.4\%). Comparing between age groups, Islam (2016) and Safari et al. (2019) have found contraceptives use to be lower among women over 35 years compared to younger women (14-24 years). While acknowledging other likely determinants of induced abortion, this decline observed in contraceptives use among younger women (14-24 years) may have some association with the $3 \%$ and $16 \%$ rates of induced abortion reported among women of the age categories of 15-19 years and 20-24 years in 2017 (Ghana Statistical Service, Ghana Health Service, \& ICF International, 2017). Therefore, policymakers would need to facilitate widespread access to modern contraceptives and promote their effective use to reduce such abortion incidences (Deschner \& Cohen, 2003).

High level of education had some significant link with the likelihood of contraceptive use; participants who had secondary and higher levels of education were 2 and 3 times more likely to use contraceptives compared with those with only primary education. Similar findings have been reported elsewhere (Aviisah et al., 2018; Grindlay et al., 2018; Habyarimana \& Ramroop, 2018; Matungulu et al.,2017).

We have also demonstrated that women aged 14-24 years with one or more living children are approximately 4 times more likely to use contraceptives, compared to those without living children. 
Analysis by Aviisah et al. (2018) using the 2003-2014 Ghana Demographic and Health Surveys also reported $67 \%$ contraceptives use in 2003 and $54 \%$ probability of contraceptives use among women with 1-3 living children in 2008. Another study conducted in 73 low-and middle- income countries including Ghana revealed that modern contraceptives use was low among married female adolescents without children (De Vargas Nunes Coll et al., 2019) . The association observed between the number of living children and contraceptives use is probably because of increasing responsibilities for caretakers, though other factors such as desire to space or limit birth by women might be critical factors.

Our study also revealed that women with prior history of abortion were $2.20(p=0.000)$ times more likely to use contraceptives compared with others without any abortion history. Finding of this study contradicts that reported by Arbab, Bener, \& Abdulmalik (2011) in Qatar pointing out that women with a history of abortion are less likely to use contraceptives than those without such history. However, our study finding corroborated that of Morris \& Prata (2018) which suggests that women with history of abortion are 1.23 times more likely to use modern contraceptives compared to those with no history of abortion. It has been reported (Borges et al., 2015) that women utilize both medical consultation and contraceptives counselling often after post-abortion. This finding probably shows that women with such experiences try to avoid its repetition and so try to access the services and as such, services should be adequately provided and made easily accessible.

We have also demonstrated that rural women aged 14-24 years who know their fertility period are 2.56 times more probable contraceptives users compared with those who do not know. This increased probability observed may be as a result of the increased conception chances a woman has during these periods. However, Amazigo et al. (2020) observed that young women are less frequent users of contraceptives and are less likely to restrict intercourse to the safe periods of their cycle when they are involved with older partners.

While acknowledging the influence of factors such as knowledge of fertility period, level of education, number of living children and history of abortion on contraceptives use among women aged 15-24years, tackling low contraceptives use will require a comprehensive multi-sectoral approach iterating through physical, social, cultural and psychosocial domains of health.

\subsection{Strengths And Limitations Of The Study}

This study is from a nationally representative sample and makes room for generalizability of study findings across Ghana. Also, Demographic and Health Surveys (DHS) are planned properly and well executed; hence the data is of high quality. Furthermore, observations with complete dataset meeting the study criteria was large. There are however some limitations with the study. Firstly, the data was obtained through a cross-sectional study design, hence preventing causations to be inferred. The survey obtained information retrospectively which has a high recall bias since participants self-reported, which spanned a 5 -year period prior to the survey. Recall bias has immense effect on coefficient estimates and overall significant testing and so interpretations/use of the findings should be done cautiously. 


\subsection{Conclusion}

The study concludes that contraceptive use in Ghana among women aged 15-24 years in rural residence is low. Independent variables (number of living children, age of participants, health insurance, knowledge of fertility period, history of abortion, parity, educational level, region of residence, and current union) were found to influence contraceptives use. History of abortion, educational level, number of living children, and knowledge of fertility period were significant predictors of contraceptives use. The Ministry of Health with their implementing agency (Ghana Health Service) need to facilitate widespread access to modern contraceptives and promote their effective use among rural women.

\section{Declarations}

The Ghana Health Service Institutional Review Board (IRB) and Committee of ORC MAcro Inc. approved Ghana Maternal Health Survey 2017 study protocol survey instruments and materials prior to the commencement of the surveys. Individual consent was also obtained during the data collection process. The current study was based on analysis of anonymised secondary data available in the public domain of Demographic Health Surveys(DHS) therefore no additional approval was necessary.is of anonymised secondary data available in the public domain of DHS therefore no additional approval was necessary.

\section{Data Availability}

The datasets generated and/or analyzed during the current study are available in the Ghana demographic and health repository, http://dhsprogram.com/data/available-datasets.cfm

\section{Conflicts of Interest}

The authors declare that there are no conflicts of interest regarding the publication of this paper.

\section{Funding}

This research did not receive any specific grant from funding agencies in the public, commercial, or notfor-profit sectors

\section{Authors' contributions}

MGS conceptualized the present study. MGS led the data extraction and analysis and wrote the first draft of the manuscript. MGS, MK, MCH, AA, contributed in the write-up of the different sections of the manuscript. MGS, VAA, MAR, RWA reviewed the draft manuscript and contributed to the final version of the manuscript. All authors read and approved the final manuscript before submission.

\section{Acknowledgement}

We want to thank Dr. Abdul Nashirudeen Mumuni (Senior Lecturer \& Head of Medical Imaging Department) at the University for Development Studies, Tamale, Ghana for his tremendous guide and 
support throughout this research process.

\section{References}

Agyemang, J., Newton, S., Nkrumah, I., Tsoka-Gwegweni, J. M., \& Cumber, S. N. (2019). Contraceptive use and associated factors among sexually active female adolescents in Atwima Kwanwoma District, Ashanti region-Ghana. Pan African Medical Journal, 32, 1-13.

https://doi.org/10.11604/pamj.2019.32.182.15344

Ahmed, S., Choi, Y., Rimon, J. G., Alzouma, S., Gichangi, P., Guiella, G., ... Tsui, A. (2019). Articles Trends in contraceptive prevalence rates in sub-Saharan Africa since the 2012 London Summit on Family Planning: results from repeated cross-sectional surveys. The Lancet Global Health, 7(7), e904-e911. https://doi.org/10.1016/S2214-109X(19)30200-1

Ahmed, S., Li, Q., Liu, L., \& Tsui, A. O. (2012). Maternal deaths averted by contraceptive use: An analysis of 172 countries. The Lancet, 380(9837), 111-125. https://doi.org/10.1016/S0140-6736(12)60478-4

Amazigo, U., Silva, N., Kaufman, J., Obikeze, D. S., International, S., Planning, F., ... Obikeze, D. S. (2020). Nigeria Sexual Activity and Contraceptive Knowledge and Use Among In-School Adolescents in Nigeria. 23(1), 28-33.

Appiah, F., Seidu, A., Opoku, B., Baatiema, L., \& Kwabena, E. (2020). SSM - Population Health Trends and determinants of contraceptive use among female adolescents in Ghana: Analysis of $2003-2014$ Demographic and Health Surveys. SSM - Population Health, 10, 100554. https://doi.org/10.1016/j.ssmph.2020.100554

Arbab, A. A., Bener, A., \& Abdulmalik, M. (2011).

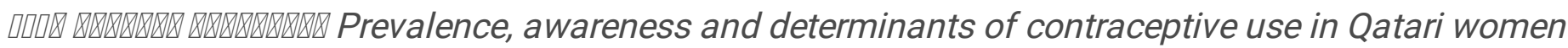

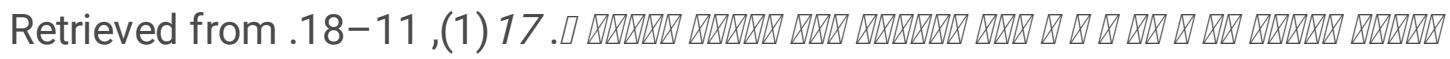
https://pdfs.semanticscholar.org/b088/6212c0034a390d8af5a829823e910bd3a00e.pdf

Aviisah, P. A., Dery, S., Atsu, B. K., Yawson, A., Alotaibi, R. M., Rezk, H. R., \& Guure, C. (2018). Modern contraceptive use among women of reproductive age in Ghana: analysis of the 2003 - 2014 Ghana Demographic and Health Surveys. 1-10.

Bakibinga, P., Matanda, D. J., Ayiko, R., Rujumba, J., Muiruri, C., Amendah, D., \& Atela, M. (2016).

Pregnancy history and current use of contraception among women of reproductive age in Burundi, Kenya, Rwanda, Tanzania and Uganda: Analysis of demographic and health survey data. BMJ Open, 6(3). https://doi.org/10.1136/bmjopen-2015-009991

Berhane, Y., Canavan, C. R., Darling, A. M., Sudfeld, C. R., \& Vuai, S. (2020). The age of opportunity: prevalence of key risk factors among adolescents 10 - 19 years of age in nine communities in subSaharan Africa. 25(1), 15-32. https://doi.org/10.1111/tmi.13339 
Buor, D. (2004). Determinants of utilisation of health services by women in rural and urban areas in Ghana Author ( $\mathrm{s}$ ): Daniel Buor Published by: Springer Stable URL:

http://www.jstor.org/stable/41147917 REFERENCES Linked references are available on JSTOR for this arti. GeoJournal, 61(1), 89-102.

Chan, Y. H. (2004). Biostatistics 202: 45(4), 149-153.

De Vargas Nunes Coll, C., Ewerling, F., Hellwig, F., \& De Barros, A. J. D. (2019). Contraception in adolescence: The influence of parity and marital status on contraceptive use in 73 low-and middleincome countries. Reproductive Health, 16(1), 1-12. https://doi.org/10.1186/s12978-019-0686-9

Deschner, A., \& Cohen, S. (2003). Contraceptive use is key to reducing abortion worldwide. ... Report on Public Policy, 35(1), 7-10. Retrieved from http://www.guttmacher.org/pubs/journals/gr060407.html

Geelhoed, D. W., Nayembil, D., Asare, K., Van Leeuwen, J. H. S., \& Van Roosmalen, J. (2002). Contraception and induced abortion in rural Ghana. Tropical Medicine and International Health, 7(8), 708-716. https://doi.org/10.1046/j.1365-3156.2002.00912.x

Ghana Maternal Health Survey 2017. (2017). Accra.

Goldenberg, T., \& Stephenson, R. (2019). Applying a deviance framework to understand modern contraceptive use in sub-Saharan Africa. PLoS ONE, 14(5), 1-13.

https://doi.org/10.1371/journal.pone.0216381

Grindlay, K., Dako-gyeke, P., Ngo, T. D., Eva, G., Gobah, L., Reiger, S. T., ... Blanchard, K. (2018).

Contraceptive use and unintended pregnancy among young women and men in Accra, Ghana. 2, 1-13.

Habyarimana, F., \& Ramroop, S. (2018). The Analysis of Socio-Economic and Demographic Factors Associated with Contraceptive Use Among Married Women of Reproductive Age in Rwanda. The Open Public Health Journal, 11(1), 348-359. https://doi.org/10.2174/1874944501811010348

Islam, A. (2016). Prevalence and Determinants of Contraceptive use among Employed and Unemployed Women in Bangladesh. International Journal of MCH and AIDS (IJMA), 5(2), 92-102.

https://doi.org/10.21106/ijma.83

Kanwal, N., Muttappallymyalil, J., Al-Sharbatti, S., \& Ismail, I. (2017). Contraceptive utilisation among mothers of reproductive age in Ajman, United Arab Emirates. Sultan Qaboos University Medical Journal, 17(1), e50-e58. https://doi.org/10.18295/squmj.2016.17.01.010

Kirkman, R., \& Chantler, E. (1993). Contraception and the prevention of sexually transmitted diseases. British Medical Bulletin, 49(1), 171-181. https://doi.org/10.1093/oxfordjournals.bmb.a072596

Matungulu CM, Ntambwe MA, llunga KS, Musau NA, llunga MT, M. K. (2017). Factors Associated with the Use of Modern Contraceptive Methods by Women in Marital Union in the City of Lubumbashi, 
Democratic. Austin J Womens Health. Austin J Womens Health, 4(4), 1022-1.

Morris, N., \& Prata, N. (2018). Abortion history and its association with current use of modern contraceptive methods in Luanda, Angola. Open Access Journal of Contraception, Volume 9, 45-55. https://doi.org/10.2147/oajc.s164736

Nonvignon, J., \& Novignon, J. (2014). Trend and determinants of contraceptive use among women of reproductive age in Ghana. Etude de La Population Africaine, 28(2), 956-967. https://doi.org/10.11564/28-0-549

Nyarko, S. H. (2020). Spatial variations and socioeconomic determinants of modern contraceptive use in Ghana: A Bayesian multilevel analysis. 1-12. https://doi.org/10.1371/journal.pone.0230139

Odonkor, S. T., Nonvignon, J., Adu, J., Okyere, M., \& Mahami, T. (2012). Sexually Transmitted Diseases ( STDS) Among Adolescents In Second Cycle Institutions In Accra, Ghana: Trends In Sexual Behaviors. $3(1), 9-17$.

Safari, W., Urassa, M., Mtenga, B., Changalucha, J., Beard, J., Church, K., ... Todd, J. (2019). Contraceptive use and discontinuation among women in rural North-West Tanzania. Contraception and Reproductive Medicine, 4(1), 1-10. https://doi.org/10.1186/s40834-019-0100-6

Schrumpf, L. A., Stephens, M. J., Nsarko, N. E., Akosah, E., Baumgartner, J. N., Ohemeng-dapaah, S., \& Watt, M. H. (2020). Side effect concerns and their impact on women 's uptake of modern family planning methods in rural Ghana: a mixed methods study. 1-8. 